\title{
Carboxy-terminal determinants of intracellular protein degradation
}

\author{
Dawn A. Parsell, Karen R. Silber, and Robert T. Sauer \\ Department of Biology, Massachusetts Institute of Technology, Cambridge, Massachusetts 02139 USA
}

\begin{abstract}
Using the amino-terminal domain of $\lambda$ repressor as a model system, we show that residues in an unstructured region at the extreme carboxyl terminus of the protein are important for determining its proteolytic susceptibility in Escherichia coli. Nonpolar amino acids are destabilizing when placed at the 5 carboxy-terminal residue positions, whereas charged and polar residues are stabilizing. The stabilizing effect of a single charged residue is greatest when it is at the terminal position and diminishes with increasing distance from the carboxyl terminus. The position of destabilizing sequences with respect to the free carboxyl terminus is important for their effect, but their distance from the folded portion of the protein is not important. Specific degradation of proteins with nonpolar carboxyl termini has been reconstituted in vitro using a partially pure, soluble fraction. This degradation is not ATP-dependent. Moreover, amino-terminal domain variants with nonpolar carboxyterminal residues are still rapidly degraded in strains that are deficient in proteolysis of abnormal proteins. These data suggest that the degradation of amino-terminal domain variants with nonpolar carboxy-terminal residues involves proteolytic components distinct from those known to be important for the turnover of unfolded proteins in $E$. coli.
\end{abstract}

[Key Words: Proteolytic determinants; protein degradation; Escherichia coli; $\lambda$ repressor]

Received October 19, 1989; revised version accepted December 6, 1989.

Intracellular protein turnover is extremely selective. Although most cellular proteins are degraded very slowly, both prokaryotic and eukaryotic cells contain proteins that are degraded rapidly. The proteins in this latter class include certain regulatory proteins, unfolded proteins and, during stress conditions, proteins that were previously stable (Goldberg and St. John 1976; Evans et al. 1983; Spindler and Berk 1984; Gottesman 1987; Straus et al. 1987; Hershko 1988). Clearly, intracellular proteolytic enzymes must have some mechanism by which they recognize specific proteins as targets for degradation.

The features of proteins that make them targets for degradation in Escherichia coli remain largely unknown. Natural substrates have been identified for two $E$. coli proteases. Protease La degrades the SulA, RcsA, and $\lambda \mathrm{N}$ proteins (Gottesman et al. 1981; Mizusawa and Gottesman 1983; Torres-Cabassa and Gottesman 1987), whereas the HflA protease degrades the $\lambda$ cII protein (Cheng et al. 1988). In both cases, however, the recognition mechanisms are undefined. Somewhat more is known about the turnover of abnormal proteins. Intracellular degradation rates of nonsense and puromycyl fragments and missense and analog-containing mutants are much more rapid than those of most wild-type proteins (Goldberg 1972; Bukhari and Zipser 1973; Zipser and Bhavsar 1976). This suggests that unfolding may increase the proteolytic susceptibility of many proteins. Abnormal protein degradation is decreased in lon and $h t p R$ mutants (Bukhari and Zipser 1973; Gottesman and Zipser 1978; Chung and Goldberg 1981; Baker et al. 1984; Goff et al. 1984; Straus et al. 1988), suggesting that protease $\mathrm{La}$ and other proteases under the control of the heat shock regulon are important for the turnover of abnormal proteins in vivo. An unfolded conformation may be an important determinant for recognition by these proteases.

We have been using the amino-terminal domain of $\lambda$ repressor to investigate the features of a protein that make it susceptible to proteolysis in E. coli. The aminoterminal domain appears to contain at least two determinants of proteolytic susceptibility. First, the thermal stability of the protein is known to be an important determinant because missense mutants with decreased thermal stabilities show correspondingly decreased intracellular half-lives (Parsell and Sauer 1989). Second, the amino acid sequence at the carboxyl terminus of the amino-terminal domain also influences its rate of intracellular degradation. Fusion of carboxy-terminal "tail" sequences to the folded portion of the protein affords proteolytic stabilization to otherwise rapidly degraded variants (Bowie and Sauer 1989; Parsell and Sauer 1989). For example, a 26-amino-acid long tail (LT) sequence was shown to decrease the intracellular proteolytic susceptibility of mutant forms of both the amino-terminal domain and another protein, the P22 Arc repressor. Studies of purified proteins containing the LT sequence indicate that these residues influence rates of degradation without affecting the structural stability of the proteins.

In this report we describe the use of deletion analysis and random and site-directed mutagenesis to characterize the features of carboxy-terminal sequences that are important in determining proteolytic susceptibility. 
We show that it is largely the polar or nonpolar character of these residues that determines the proteolytic sensitivity of the protein. Moreover, we provide evidence to suggest that the turnover of proteins with destabilizing carboxy-terminal sequences may involve a proteolytic pathway that is distinct from those currently known in E. coli.

\section{Results}

Variants of the amino-terminal domain of $\lambda$ repressor were studied to assess the effect of different carboxy-terminal sequences on the proteolytic susceptibility of the protein. Each of these amino-terminal domain proteins has the same basic structure. The amino-terminal 92 residues of the protein are folded into a stable, predominantly $\alpha$-helical structure (Pabo and Lewis 1982). These residues are followed by carboxy-terminal extensions, from 10 to 26 residues in length, that are predominantly unstructured (Weiss et al. 1987a; Bowie and Sauer 1989; Parsell and Sauer 1989).

\section{Deletion analysis of a tail sequence}

We began our analysis by studying the properties of the 26-residue LT sequence (Bowie and Sauer 1989) (Fig. 1A) that are important for its ability to protect the aminoterminal domain from intracellular degradation. To this end, we constructed the set of five deletion derivatives shown in Figure 1A and determined their intracellular levels by SDS-gel electrophoresis of cell lysates, as shown in Figure 1B. The LT, LT-a, and LT-b proteins are present at the highest steady-state levels, the LT-d protein is present at a moderate level, and the LT-c and LT-e proteins are present at very low levels. Pulsechase experiments were performed to monitor degradation directly. During the course of a 3-hr chase, the LT, LT-a, LT-b, and LT-d proteins showed virtually no degradation, the LT-c protein was degraded with a half-life of $\sim 60$ min and the LT-e protein was degraded with a halflife of about $40 \mathrm{~min}$. Although the LT-c and LT-e variants are relatively long-lived, they are not seen to accumulate in the steady-state experiment of Figure 1B. Presumably, this occurs because degradation proceeds more rapidly in the rich media used for the steady-state experiment than in the minimal media required for pulse-chase experiments. The LT-c and LT-e proteins do accumulate when steady-state levels are monitored in minimal media (data not shown).

These experiments revealed the following: (1) The entire LT sequence is not required for proteolytic stabilization of the amino-terminal domain. The LT-d variant is proteolytically stable even though it is 13 residues shorter than the LT protein. (2) Stabilization is not strictly correlated with the length of the extension. The LT-c variant is 5 amino acids longer than the LT-d variant but it is less stable. (3) Variants with charged and highly polar amino acids at or near the carboxyl terminus are more stable than those with hydrophobic residues at these positions. The unstable LT-e and LT-c variants have no charged amino acids, the moderately stable LT-d variant has one charged residue, and the stable LT, LT-a, and LT-b variants have at least two charged amino acids in the 5 carboxy-terminal residue positions. These data suggest that the presence of charged and polar amino acids near the carboxyl terminus of the protein may be important for determining its rate of intracellular degradation.

\section{Randomization of carboxy-terminal residues}

To probe further the role of carboxy-terminal residues in conferring proteolytic stability, we randomly mutagenized these amino acids in a fragment of $\lambda$ repressor containing residues $1-102$. This protein is composed of the 92-residue amino-terminal domain and an unstructured 10-residue carboxy-terminal sequence Met-Gln-Pro-SerLeu-Arg-Ser-Glu-Tyr-Glu ${ }^{102}$. Each of the last 5 residues of this protein is charged or polar.

The 5 carboxy-terminal residues of the 1-102 protein were randomly altered using cassette mutagenesis (see Experimental procedures) so that any amino acid could occupy the mutagenized positions. Several hundred transformants were screened for 1-102 protein levels by
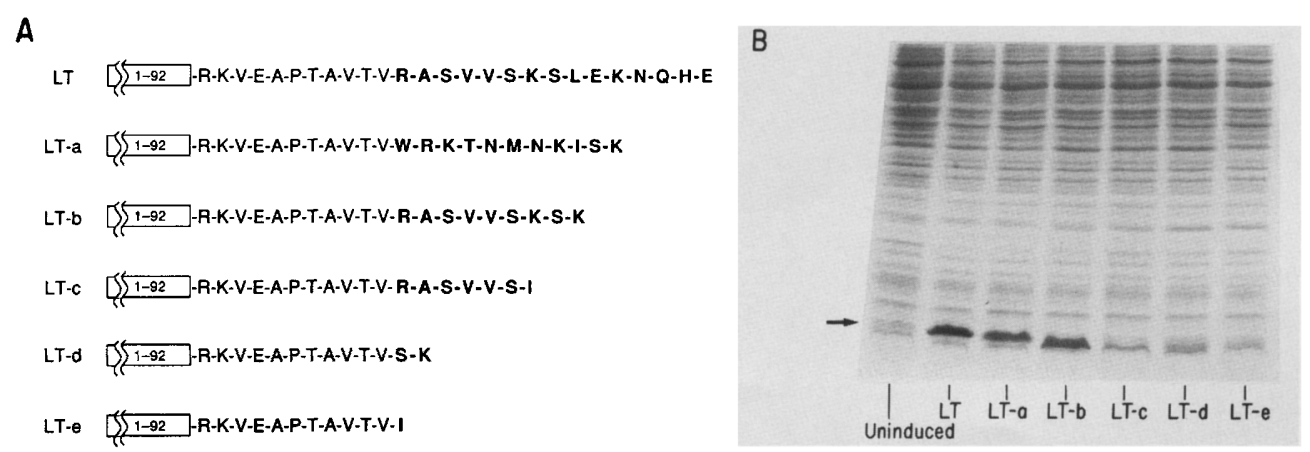

Figure 1. (A) Sequences of the LT extension and deletion derivatives fused to residues 1-92 of $\lambda$ repressor. The residues in boldface type are those that differ among the variants. $(B)$ Coomassie-stained Laemmli gel showing the steady-state levels of the proteins in $A$. $(\rightarrow)$ The approximate position of the LT variants. The uninduced lane is the same as the LT lane, except that IPTG was not added. 
SDS-gel electrophoresis. Thirteen candidates showed protein levels similar to the wild-type and were designated as "stable." Eighteen candidates contained no detectable 1-102 protein and were designated "unstable." The remaining candidates showed intermediate levels of 1-102 protein and were not studied further. The genes encoding the proteins in the stable and unstable classes were sequenced. The carboxy-terminal residues of each of these proteins are shown in Table 1, and a Coomassie-stained gel showing the steady-state levels of several proteins from the stable and unstable classes is shown in Figure 2. Pulse-chase experiments confirmed that the low steady-state levels of proteins in the unstable class correlated with their increased susceptibility to proteolysis (Table 1). Comparison of the rates of degradation of members of the unstable and stable classes shows that the identity of the five carboxy-terminal residues can cause a change of 40 -fold or greater in intracellular half-life. For example, the \#105 protein (Trp-ValAla-Ala-Ala) has a half-life of $15 \mathrm{~min}$, whereas the halflife of the wild-type protein (Arg-Ser-Glu-Tyr-Glu) is $>600 \mathrm{~min}$. Thus, although it is not certain exactly how many residues at the carboxyl terminus comprise the proteolytic determinant, alteration of the last 5 residues is sufficient to confer a large effect.

The carboxy-terminal pentapeptides of proteins in the stable class contain $39 \%$ charged or highly polar residues, $44 \%$ neutral or moderately polar residues and only $17 \%$ hydrophobic residues. ${ }^{1}$ In contrast, the carboxy-terminal pentapeptides of proteins in the unstable class contain only $3 \%$ charged or highly polar, $36 \%$ neutral or moderately polar, and $61 \%$ hydrophobic residues. Clearly, the carboxy-terminal residues of proteins in the unstable class are rather hydrophobic, while those in the stable class are rather hydrophilic. The total hydrophobicity of the side chains of the carboxy-terminal pentapeptides of each of the 1-102 variants is given in Table 1. These values were determined using a hydrophobicity scale (Eisenberg and McLachlan 1986) based on the data of Fauchere and Pliska (1983). In this scale, the glycine side chain has a free energy of transfer of $0 \mathrm{kcal} / \mathrm{mole}$, amino acids that are more hydrophobic than glycine have positive free energies, and those that are more hydrophilic than glycine have negative free energies.

As shown in Figure $3 \mathrm{~A}$, the carboxy-terminal pentapeptides of 1-102 proteins in the stable and unstable classes fall into discrete classes with respect to hydrophobicity. For comparison, the distribution of carboxyterminal hydrophobicities for other $E$. coli proteins is shown in Figure 3B. ${ }^{2}$ The average hydrophobicity of the last 5 residues for the stable class $(0.2 \pm 1.3 \mathrm{kcal} / \mathrm{mole})$ is only slightly more hydrophilic than that of the average $E$. coli protein $(1.4 \pm 2.9 \mathrm{kcal} / \mathrm{mole})$, whereas the unstable proteins have carboxy-terminal sequences that are considerably more hydrophobic $(7.2 \pm 1.1$

${ }^{1}$ Amino acids are grouped as follows (J.U. Bowie, N.D. Clarke, C.O. Pabo, and R.T. Sauer, in prep.): (Charged/highly polar) Gln, Asn, Glu, Asp, Lys, Arg; (neutral/moderately polar) Tyr, Pro, Ala, Thr, His, Gly, Ser; (hydrophobic) Trp, Ile, Phe, Leu, Met, Val, Cys. $\mathrm{kcal} / \mathrm{mole}$ ) than most proteins. When carboxy-terminal hydrophobicities are calculated for the amino-terminal domain derivatives shown in Figure 1, similar results are obtained. The LT, LT-a, LT-b, and LT-d proteins have half-lives $>3 \mathrm{hr}$ and hydrophobicities that fall within the stable distribution in Figure 3A. In contrast, the LT-c and LT-e proteins have half-lives of $\sim 1 \mathrm{hr}$ or less and hydrophobicities that fall within the unstable distribution in Figure 3A. Hence, for both the LT and 1-102 variants of the amino-terminal domain, the presence of charged and polar residues at the carboxyl terminus results in proteins that are stable, whereas nonpolar sequences result in proteins that are degraded more rapidly.

It is important to note that our results do not suggest a linear correlation between carboxy-terminal hydrophobicity and intracellular stability. For example, the \#105 variant (Trp-Val-Ala-Ala-Ala) is degraded faster than the \#15 variant (Cys-Val-Val-Leu-Val), even though the latter sequence is more hydrophobic. There are undoubtedly preferences for particular nonpolar amino acids at particular positions relative to the carboxyl terminus. Indeed, this can be seen when just the carboxy-terminal residue of the wild-type 1-102 protein is mutated. The carboxy-terminal glutamic acid of the 1-102 protein was replaced with each of the other 19 amino acids. The relative steady-state levels of these mutants were (Asp, Glu, Lys $)>$ (Arg, Gln, Asn, Ser $)>$ (His, Thr, Pro, Tyr, Phe, Leu, Trp $)>($ Gly, Met, Ile $)>($ Val, Cys Ala). Although charged and polar substitutions result in more stable proteins and nonpolar substitutions result in more rapidly degraded variants, the most destabilizing amino acids at the last residue position (i.e., Ala, Cys, Val) are not the most hydrophobic ones. Proteins containing alanine, cysteine, or valine at their carboxyl terminus were degraded with half-lives of $2-3$ hours in minimal media (data not shown). Because no single amino acid substitution at the carboxy-terminal residue was as destabilizing as any of the pentapeptide sequences in the unstable class of Table 1, the proteolytic determinant must consist of more than the last residue.

The stabilizing effect of a charged residue is greatest at the carboxyl terminus

To obtain more information about the stabilizing effect of a charged residue near the carboxyl terminus, we constructed a set of $1-102$ variants with either five alanines or different combinations of four alanines and one aspartic acid at the carboxyl terminus of the protein. This set of variants allows examination of the effect of moving a single charged residue progressively closer to the carboxyl terminus. As shown in Table 2, the charged aspartic acid has the greatest stabilizing influence when it is the carboxy-terminal residue of the protein. Its stabilizing effect is diminished somewhat when it is the penultimate carboxy-terminal residue, and is lessened

${ }^{2}$ The distribution of hydrophobicites shown in Fig. 3B is very similar to that seen for random pentapeptides in $E$. coli proteins. 
Table 1. Sequences of the 5 carboxy-terminal residues of unstable and stable 1-102 variants

\begin{tabular}{|c|c|c|c|}
\hline Isolate & Sequence & Hydrophobicity & $\begin{array}{l}\text { Half-life } \\
\text { (min) }\end{array}$ \\
\hline \multicolumn{4}{|c|}{ Unstable } \\
\hline \#6 & Arg -Met- Pro - Ala - Leu & 4.0 & 27 \\
\hline \#13 & Val - Val - Val - Leu - Pro & 8.3 & - \\
\hline$\# 14$ & Cys - Leu - Pro - Gly - Leu & 7.0 & - \\
\hline$\# 15$ & Cys - Val - Val - Leu - Val & 8.6 & 44 \\
\hline$\# 17$ & Gly - Pro - Leu - Ala - Phe & 6.2 & - \\
\hline \#19 & Arg - Trp - Val - Leu - Phe & 8.1 & - \\
\hline$\# 27$ & Pro - Trp - Val - Gly - Leu & 8.0 & - \\
\hline \#29 & Val - Tyr - Ala - Ile - Cys & 7.2 & 30 \\
\hline$\# 34$ & Tyr - Val - Met - Trp - Ala & 8.1 & 15 \\
\hline \#36 & Ile - Ser - Val - Thr - Leu & 6.7 & - \\
\hline$\# 43$ & Val - Trp - Leu - Thr - Ala & 7.8 & - \\
\hline \#44 & Gly - Tyr - Cys - Leu - Leu & 7.3 & - \\
\hline \#53 & Met - Ser - Leu - Pro - Thr & 5.3 & - \\
\hline$\# 104$ & Ile - His - Trp - Val - Thr & 7.7 & 16 \\
\hline \#105 & Trp - Val - Ala - Ala - Ala & 6.0 & 15 \\
\hline \#108 & Ser - Leu-Leu - Trp - Ser & 7.6 & 17 \\
\hline \#109 & Trp - Val - Cys - Val - Ser & 7.7 & - \\
\hline$\# 110$ & Trp - Leu - Asp - Gly - Trp & 7.4 & 31 \\
\hline & & mean $=7.2 \pm 1.1$ & \\
\hline \multicolumn{4}{|c|}{ Stable } \\
\hline WT & Arg - Ser - Glu-Tyr - Glu & -1.8 & $>600$ \\
\hline$\# 2$ & Gln-Asp- Ile - Gln-Ala & 1.2 & - \\
\hline$\# 5$ & Val - Ala-Ser - Asn-Arg & -0.2 & 132 \\
\hline \#7 & Gly - Gln - Ala - Gly - Glu & -0.8 & - \\
\hline \#9 & Asp-Thr - Gly - Ala - His & -0.1 & - \\
\hline$\# 28$ & His - Val - Gly - Arg - Phe & 2.9 & 162 \\
\hline$\# 56$ & Tyr - Arg - Leu - Lys - Gly & 0.9 & - \\
\hline$\# 58$ & Asp- Ser - Leu - Ala - Arg & 0.3 & - \\
\hline$\# 60$ & Ile - Arg - Ala - Pro - Arg & 1.1 & - \\
\hline \#61 & Arg - Ile - Arg - Ala - Gly & 0.1 & - \\
\hline$\# 62$ & Ser - Gly - Arg - Ala - Ser & -1.0 & 229 \\
\hline$\# 71$ & Pro - Arg - Cys - Leu - Lys & 1.9 & - \\
\hline$\# 80$ & Gly - Val - Arg - Arg - Val & 0.6 & - \\
\hline \multirow[t]{2}{*}{ \#81 } & Gly - Gly - Gly - Arg - Asn & -2.2 & - \\
\hline & & mean $=0.2 \pm 1.3$ & \\
\hline
\end{tabular}

Hydrophobicity values were determined using the scale of Fauchere and Pliska (1983), as described. Half-lives of representative mutants were determined by pulse-chase experiments.

further as its distance from the free carboxyl terminus is increased. Thus, residues closer to the carboxyl terminus appear to play a greater role in determining the proteolytic susceptibility of the protein than those farther away.

The stabilizing effect of a carboxy-terminal sequence containing a charged amino acid can be further enhanced by the presence of additional charged residues. For example, as shown in Table 2, an amino-terminal domain variant that ends with five aspartic acids is not detectably degraded during a 9-hr chase. In this case, the stabilizing effect is greater than the combined effects of the five single aspartic acid substitutions.

\section{Positioning of the carboxy-terminal determinant}

The results discussed above suggest that the position of a destabilizing sequence in relation to the free carboxyl terminus of the protein is critical for its effect. If this is true, then one should be able to extend the half-life of an unstable variant simply by adding charged residues to its carboxyl terminus. To test this, we constructed an amino-terminal domain gene that encoded one of the rapidly degraded variants, \#105, with two additional arginines at its carboxyl terminus (Trp-Val-Ala-Ala-AlaArg-Arg ${ }^{104}$ ). As shown in Figure 4, this variant (\#105Arg-Arg) is considerably more stable than the \#105 variant. As a control, the rate of degradation of a compositionally identical amino-terminal domain variant with the carboxy-terminal sequence Arg-Arg-Trp-ValAla-Ala-Ala ${ }^{104}$ was measured and was found to be within experimental error $\left(t_{1 / 2} \cong 17 \mathrm{~min}\right)$ of that of the \#105 protein $\left(t_{1 / 2} \cong 15 \mathrm{~min}\right)$. These experiments provide further evidence that a nonpolar sequence must occur at the carboxyl terminus for its destabilizing effect to be maximal. 


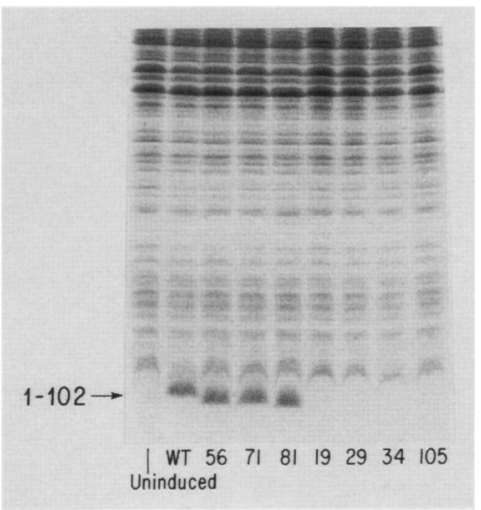

Figure 2. Coomassie-stained Laemmli gel showing steadystate levels of representative $1-102$ variants. $(\rightarrow)$ The position of the $1-102$ variants. Mutations in the last 20 amino acids of the 1-102 protein often cause small differences in mobility on Laemmli gels. Numbers below lanes refer to the isolate numbers shown in Table 1 . The uninduced lane is the same as the wild-type (WT) lane, except that IPTG was not added.

As mentioned previously, the $1-102$ protein is composed of an amino-terminal 92-residue folded domain, followed by an unstructured 10-residue sequence. To test whether the positioning of a destabilizing carboxyterminal sequence with respect to the globular "body" of the protein was important for its effect, we moved a destabilizing carboxy-terminal sequence farther away from the folded portion of the protein by replacing the last 5 residues of the LT protein with those from the unstable \#105 mutant (Trp-Val-Ala-Ala-Ala). This variant (LT\#105) and the \#105 variant have identical destabilizing sequences located 21 and 5 residues from the folded part of the amino-terminal domain, respectively. The degradation rates of these two variants were found to be virtually identical (Fig. 5). Thus, moving a destabilizing sequence relative to the folded portion of the protein does not appear to alter its destabilizing effect.

\section{Destabilizing carboxy-terminal sequences do not} decrease the thermal stability of the protein

It is formally possible that sequence determinants at the carboxyl terminus could affect intracellular degradation by altering the structural stability of the protein (Parsell and Sauer 1989|. This mechanism seems unlikely, however, because the carboxy-terminal extensions of the wild-type 1-102 and LT proteins do not interact with the folded portion of these proteins or affect their thermal stabilities (Pabo and Lewis 1982; Pabo et al. 1979; Weiss et al. 1987b; Bowie and Sauer 1989). To test whether a destabilizing carboxy-terminal sequence altered the thermodynamic stability of the 1-102 protein, we purified a small quantity of the rapidly degraded \#105 variant. This protein was found to have a circular dichroism spectrum similar to that of the wild-type amino-terminal domain at low temperature and to be as thermally stable as the wild-type protein (Fig. 6). This result makes it exceedingly unlikely that the effects of carboxy-terminal sequences depend on their ability to disrupt the folded structure of the proteins in which they reside.

\section{Degradation of proteins with destabilizing carboxyl termini is distinct from degradation of unfolded proteins}

The cellular proteins involved in the degradation of proteins with destabilizing carboxy-terminal sequences appear to be different from those involved in the degradation of unfolded proteins. Protease $\mathrm{La}$ and other heat shock proteins have been shown to be important for the intracellular turnover of unfolded or abnormal polypeptides (Bukhari and Zipser 1973; Gottesman and Zipser 1978; Chung and Goldberg 1981; Straus et al. 1988). However, we do not observe significant stabilization of proteins with destabilizing carboxy-terminal sequences in E. coli strains deficient in these systems. Table 3 shows the results of pulse-chase experiments performed on two amino-terminal domain variants in isogenic $l o n^{+} /$lon $^{-}$and $h t p R^{+} / h t p R^{-}$strains. The \#105 protein, which has wild-type thermal stability $\left(T_{\mathrm{m}}=\right.$ $\left.54^{\circ} \mathrm{C}\right)$ and a destabilizing carboxy-terminal sequence, shows no stabilization in the $h t p R^{-}$or lon- strain. In contrast, the LG57 protein, which is thermally unstable

A

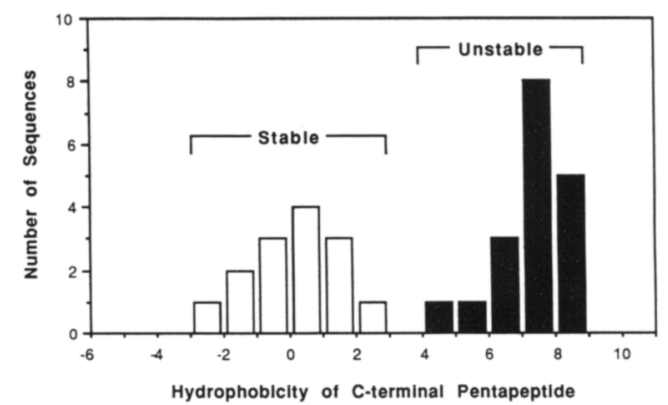

B

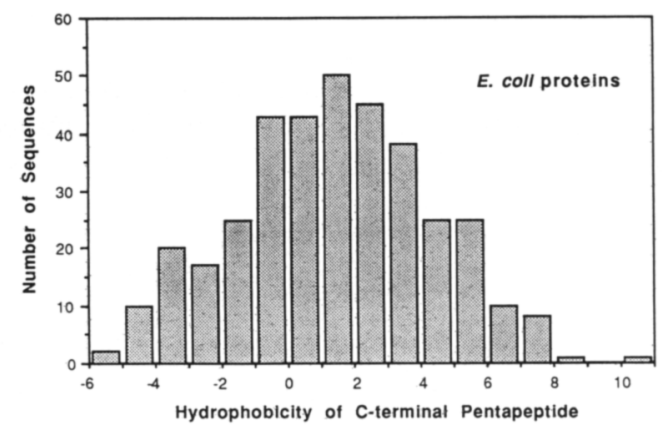

Figure 3. The distribution of the hydrophobicities of the carboxy-terminal 5 residues of the $1-102$ variants listed in Table 1 $(A)$, and $E$. coli proteins $(B)$. Hydrophobicity values in units of $\mathrm{kcal} / \mathrm{mole}$ were calculated as described. The $E$. coli proteins shown in $B$ are those from the Protein Identification Resource (1986) Protein Sequence Database (National Biomedical Research Foundation, Washington, D.C.) Release 15, excluding protein sequences that were described to be membrane-associated, secreted, fragments, or leader peptides. 
Table 2. Degradation of 1-102 amino-terminal domain variants containing alanine or aspartic acid at the last five carboxy-terminal residue positions

\begin{tabular}{lc}
\hline $\begin{array}{l}\text { Sequence of carboxy- } \\
\text { terminal pentapeptide }\end{array}$ & $\begin{array}{l}\text { Half-life } \pm \text { S.D. } \\
\text { (min) }\end{array}$ \\
\hline Ala-Ala-Ala-Ala-Ala & $22 \pm 3$ \\
Asp-Ala-Ala-Ala-Ala & $38 \pm 8$ \\
Ala-Asp-Ala-Ala-Ala & $34 \pm 9$ \\
Ala-Ala-Asp-Ala-Ala & $48 \pm 8$ \\
Ala-Ala-Ala-Asp-Ala & $91 \pm 21$ \\
Ala-Ala-Ala-Ala-Asp & $143 \pm 18$ \\
Asp-Asp-Asp-Asp-Asp & $>540$ \\
\hline
\end{tabular}

The values are mean half-lives \pm S.D. calculated from three separate pulse-chase experiments.

$\left(T_{\mathrm{m}} \leqq 10^{\circ} \mathrm{C}\right.$; Parsell and Sauer 1989$)$ but has a stabilizing carboxy-terminal sequence (Arg-Ser-Glu-Tyr-Glu), is dramatically stabilized by mutations in lon and $h t p R$. Thus, the degradation of variants with destabilizing carboxy-terminal sequences does not appear to require the heat shock proteins that are important for the degradation of unfolded proteins.

\section{Degradation in vitro of proteins with nonpolar carboxy-terminal sequences}

Using an assay that monitors release of acid-soluble peptides from ${ }^{35}$ S-labeled \#105 or wild-type protein, we have partially purified a proteolytic activity that specifically degrades the \#105 variant but not the wild-type 1-102. This activity is not membrane-associated and remains soluble during several steps of purification (see Experimental procedures). As shown in Figure 7, the \#105 protein (Trp-Val-Ala-Ala-Ala ${ }^{102}$ ) is substantially degraded to acid-soluble peptides during the course of a 24-hr incubation with this activity, whereas no degradation of the wild-type protein is seen (Arg-Ser-Glu-Tyr$\mathrm{Glu}^{102}$. The data of Figure 7 also show that unlike the degradation mediated by the $\mathrm{La}$ and $\mathrm{Clp}$ proteases of $E$. coli (Bukhari and Zipser 1973; Gottesman and Zipser 1978; Chung and Goldberg 1981; Katayama-Fujimura et

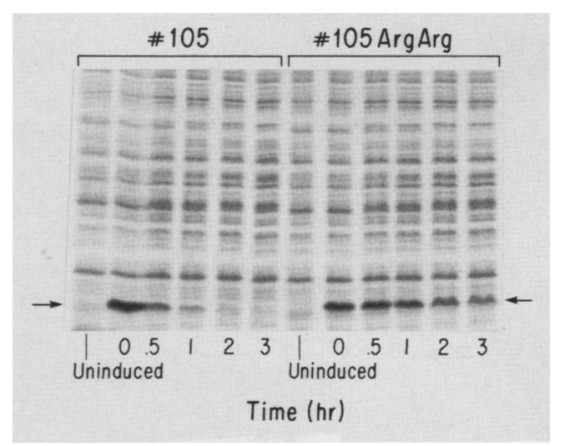

Figure 4. Pulse-chase analysis of amino-terminal domain variants containing the carboxy-terminal sequences Trp-ValAla-Ala-Ala ${ }^{102}$ (\#105) or Trp-Val-Ala-Ala-Ala-Arg-Arg ${ }^{104}$ (\#105ArgArg). Arrows indicate the positions of the amino-terminal domain proteins.

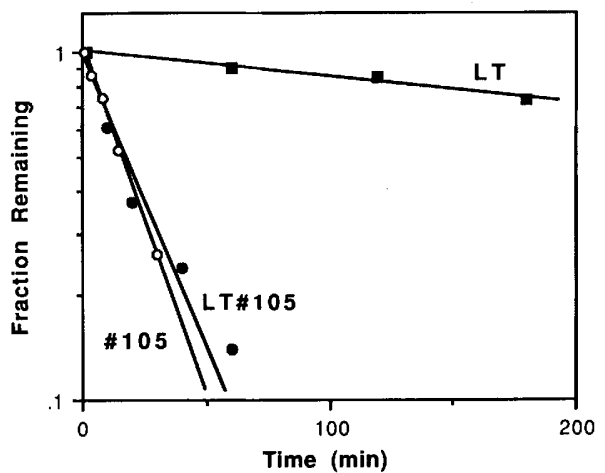

Figure 5 Effect of distance from the globular portion of the amino-terminal domain on the destabilizing ability of a hydrophobic carboxy-terminal sequence. Rates of degradation of three amino-terminal domain variants were determined by pulse-chase experiments. The results shown are averaged from three separate experiments for each variant. In the LT\#105 variant, the last 5 residues of the $\mathrm{LT}$ protein were replaced with the sequence Trp-Val-Ala-Ala-Ala using cassette mutagenesis. The half-lives for these variants are LT $>3 \mathrm{hr} ; \# 105=15 \pm 1$ $\min$; LT\#105 = $21 \pm 3 \mathrm{~min}$.

al. 1987; Katayama et al. 1988), degradation of the \#105 variant proceeds in an ATP-independent manner. In principle, nonpolar carboxy-terminal sequences may act to enhance the proteolytic sensitivity of a protein indirectly by facilitating aggregation or localization to the membrane. However, these possibilities seem unlikely, as degradation in vitro proceeds in a soluble system lacking membranes or obviously aggregated material. Moreover, preliminary results from cellular fractionation experiments suggest that the rapidly degraded \#105 variant is also soluble in the cell.

\section{Discussion}

Using variants of the amino-terminal domain of $\lambda$ repressor, we have shown that the hydropathic character of residues at and near the carboxyl terminus of the protein is an important determinant of its intracellular pro-

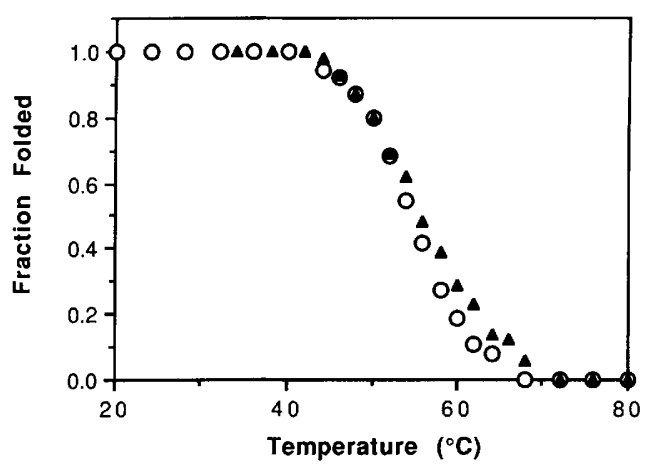

Figure 6. Thermal denaturation of wild-type 1-102 and \#105 proteins. The fraction of each protein in the folded form was determined from circular dichroism measurements at $222 \mathrm{~nm}$. (O) 1-102; (A) \#105. 
Table 3. Degradation of amino-terminal domain variants in proteolytically deficient strains

\begin{tabular}{lcc}
\hline & \multicolumn{2}{c}{ Half-lives $^{\mathrm{a}}$} \\
\cline { 2 - 3 } Protein & lon-/lon & htpR \\
\hline \#105 & $1.3 \pm 0.4$ & $1.3 \pm 0.3$ \\
LG57 & $3.2 \pm 0.9$ & $>8$ \\
\hline
\end{tabular}

The values are mean ratios of half-lives \pm S.D. calculated from at least three separate pulse-chase experiments. The mean halflife of \#105 is $14 \mathrm{~min}$ in strain $\mathrm{X} 90$ at $37^{\circ} \mathrm{C}$ and $119 \mathrm{~min}$ in strain CAG2041 at $30^{\circ} \mathrm{C}$. The mean half-life of LG57 is $18 \mathrm{~min}$ in strain X90 at $37^{\circ} \mathrm{C}$ and $22 \mathrm{~min}$ in strain CAG2041 at $30^{\circ} \mathrm{C}$. The ratio of half-lives in the isogenic lon-/lon ${ }^{+}$strains AP401/X90; the ratio of half-lives in the isogenic $h t p R^{-} / h t p R^{+}$ strains CAG2039/CAG2041.

teolytic susceptibility. In an experiment in which the last 5 amino acids of the protein were randomized, stable and unstable variants fell into discrete classes with respect to hydrophobicity. In addition to the general requirement that a destabilizing carboxy-terminal sequence be nonpolar, there appear to be preferences for particular amino acids at particular positions, with residues closer to the carboxyl terminus playing a more important role than those farther away. The position of a destabilizing sequence with respect to the free carboxyl terminus of the protein is important for its function, but its distance from the globular portion of the protein does not appear to be important.

The enzymes involved in turnover of variants with destabilizing carboxy-terminal sequences are not affected by mutations in the heat shock response and thus seem to be distinct from those involved in the degradation of unfolded proteins. Degradation in vitro of a variant with a destabilizing carboxy-terminal sequence is ATP-independent and requires proteins present in a soluble $E$. coli fraction. Clearly, the enzyme(s) responsible for this degradation will need to be purified to address detailed questions of mechanism.

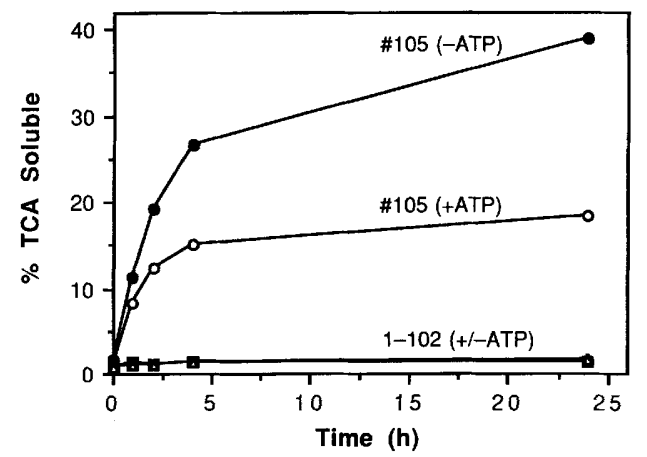

Figure 7. Degradation in vitro of an amino-terminal domain variant with a destabilizing carboxy-terminal sequence. Degradation of ${ }^{35}$ S-labeled wild-type 1-102 protein or the \#105 variant to TCA-soluble peptides was measured in the presence of a partially purified, soluble $E$. coli fraction as described in Experimental procedures. (O) \#105; (O) \#105 + ATP

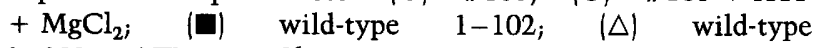
$1-102+\mathrm{ATP}+\mathrm{MgCl}_{2}$.
Carboxy-terminal sequences could be protease binding sites

It seems likely that carboxy-terminal residues function as sites of interaction between the protein and the proteolytic machinery of the cell. For example, a hydrophobic sequence close to the free carboxyl terminus of a protein could act as a binding site for a protease. Proteases with specificity for the carboxyl termini of their substrates are known. For example, carboxypeptidases degrade proteins progressively from their carboxyl termini. Alternatively, the carboxy-terminal residues of the amino-terminal domain variants could comprise a binding site for an endoprotease.

If the carboxy-terminal residues do form a binding site for a protease, then the binding would need to rely on the general hydrophobic nature of the carboxy-terminal sequences, as many different sequences are destabilizing. There is precedent for the idea that degenerate hydrophobic signals can provide specific recognition. Kaiser et al. found that $20 \%$ of random sequences could function as a signal sequence to direct secretion of the yeast invertase protein, with the overall hydrophobic nature of the sequences appearing to be the most conserved feature (Kaiser et al. 1987). Instead of hydrophobic carboxyl termini forming binding sites for proteases, it is formally possible that proteins that act to block proteolysis could bind to hydrophilic sequences at the carboxyl terminus of the protein. This model seems less likely, however, because sequences that are either positively or negatively charged seem to block degradation and it is difficult to imagine that both kinds of sequences could be bound equally well by an "antiprotease"

\section{Interaction of sequence and structural signals in determining proteolysis rates}

Both thermal stability and the carboxy-terminal sequence appear to be important in determining the intracellular proteolytic susceptibility of the amino-terminal domain and its variants (Bowie and Sauer 1989; Parsell and Sauer 1989|. How might these determinants interact in vivo? The fact that mutations in the lon and $h t p R$ genes substantially reduce degradation of unfolded variants but have little or no effect on the degradation of variants containing destabilizing carboxy-terminal sequences suggests that these determinants act independently. The carboxy-terminal residues of the variants of the amino-terminal domain studied here are presumably accessible in the native protein, as they are not part of the folded structure. If carboxy-terminal sequences are important determinants of proteolytic susceptibility in other proteins, the thermal stabilities of these proteins may be important not only for making them sensitive to the proteases of the lon and $h t p R$ pathways, but also for making their carboxy-terminal sequences accessible for recognition by other proteases.

Recent experiments in several other organisms suggest that the use of multiple determinants of proteolytic 
susceptibility may be a general feature of the intracellular turnover of proteins (Dice 1987). In yeast and mammalian cells, for example, ubiquitin-dependent degradation of certain proteins appears to rely on the identity of the amino-terminal amino acid, on the presence of a nearby lysine residue, and on the substrate being in an unfolded conformation (Bachmair et al. 1986; Bachmair and Varshavsky 1989; Dunten and Cohen 1989).

\section{General importance of carboxy-terminal proteolytic determinants}

Are carboxy-terminal sequences important for determining the rates of degradation of other proteins in $E$. coli? There are a few examples that suggest that this may be the case. A point mutation at the penultimate residue of P22 Arc repressor has been isolated that stabilizes the protein against proteolysis (Bowie and Sauer 1989). Arc ends with the sequence Gly-Arg-Ile-Gly-Ala; the mutant with increased half-life ends with the more hydrophilic sequence (Gly-Arg-Ile-Asp-Ala). It has also been reported that attachment of 6 arginine residues to the carboxyl terminus of the urogastrone protein affords it proteolytic stabilization in E. coli (Smith et al. 1984).

Protease(s) that degrade polypeptides with hydrophobic carboxy-terminal residues may also be important in an intermediate step in the turnover of some cellular proteins. Protease $\mathrm{La}$, for example, cleaves the $\lambda \mathrm{N}$ protein in vitro into fragments containing predominantly alanine or leucine at their carboxyl termini (Maurizi 1987). If La degradation of $\mathrm{N}$ protein in vivo generates similar fragments, these fragments may be further degraded by protease(s) that recognize their carboxy-terminal residues.

\section{Experimental procedures}

\section{Bacterial strains}

The following $E$. coli $\mathrm{K}-12$ strains were used in this work: $\mathrm{X} 90$ (Amman et al. 1983) is ara $\Delta$ (lac prol nalA argEam rif thi-1; AP401 (A. Pakula, unpubl.) is X90 lon :: minitet; CAG2039 (a gift from C. Gross) is ara $\Delta$ (lac pro) thr trpam supCts htpRam165/F' lac1Q lacZ:: Tn5; CAG204l (Grossman et al. 1987) is CAG2039 htpR ${ }^{+}$; MM294 (Hanahan 1983) is endA1 hsdr17 $\left(\mathrm{r}_{\mathrm{K}}-\mathrm{m}_{\mathrm{K}}{ }^{+}\right)$supE44 thi-1.

\section{Sequencing}

Plasmids used here have an M13 origin of replication to facilitate sequencing of the cloned genes. Single-stranded plasmid DNA was prepared as described (Vershon et al. 1986), and DNA sequences were determined by the method of Sanger (Sanger et al. 1977) using Sequenase reagents and procedures from United States Biochemical.

\section{Construction of deletion derivatives}

Plasmid p1-92LT is a pBR322-based plasmid (with an M13 origin of replication) in which the amino-terminal domain LT gene is transcribed from the $P_{t a c}$ promoter. The DNA encoding the LT extension was synthesized to include unique HindIII,
EcoRV, BssHII, and BstXI restriction sites. Deletion derivatives were constructed by digesting p1-92LT with various restriction enzymes, thereby cleaving small fragments from the LT coding sequence (Maniatis et al. 1982). The resulting single-stranded extensions were removed by treatment with mung bean nuclease (New England BioLabs), and plasmid DNA was ligated and transformed into cells of $E$. coli strain $\mathrm{X} 90 \mathrm{~F}^{\prime} l a c I^{\mathrm{Q}}$.

\section{Cassette mutagenesis}

The codons for the carboxy-terminal 5 residues of the $1-102$ amino-terminal domain fragment of $\lambda$ repressor were randomized using cassette mutagenesis (Oliphant et al. 1986). Oligonucleotide cassettes were synthesized in which each of the four bases was present at the first and second positions, and guanine and cytosine were present at the third position of each of the last 5 codons of the 1-102 gene. These cassettes encode each of the 20 naturally occurring amino acids at each of the last five positions of the 1-102 protein. Mutagenized cassettes were ligated into an M13 origin-containing plasmid encoding the 1-102 gene transcribed from the $P_{t a c}$ promoter and DNA was transformed into cells of $E$. coli strain X90 F'lacI lacZ :: Tn5 using the method of Hanahan (1983). A variation on this method was used to construct the 1-102 variants containing alanine and aspartate at each of the last 5 residue positions. Oligonucleotide cassettes were synthesized that encoded guanine at the first base, cytosine or adenine at the second base and cytosine at the third base position of each of the last 5 codons of the 1-102 gene. These cassettes were ligated, transformed, and sequenced as described above.

\section{Steady-state level determinations}

$E$. coli cells bearing plasmids encoding amino-terminal domain variants were grown at $37^{\circ} \mathrm{C}$ in $\mathrm{LB}$ broth supplemented with ampicillin $(100 \mu \mathrm{g} / \mathrm{ml})$ to an $\mathrm{OD}_{600}$ of $\sim 0.7$. Tac-promoter mediated transcription of the variants was induced with $1 \mathrm{~mm}$ isopropyl-thio- $\beta$-D-galactoside (IPTG), and cells were grown for an additional $3 \mathrm{hr}$ before harvesting. Cells were lysed by boiling in Laemmli sample buffer and lysates were electrophoresed on 15\% SDS-polyacrylamide gels (Laemmli 1970).

\section{Pulse-chase experiments}

Cultures of $E$. coli containing plasmids encoding wild-type or mutant variants of the amino-terminal domain were grown at $37^{\circ} \mathrm{C}$ to an $\mathrm{OD}_{600}$ of $0.2-0.3$ in $\mathrm{M} 9$ minimal medium (Miller 1972) supplemented with ampicillin $(100 \mu \mathrm{g} / \mathrm{ml})$ and each of the 20 naturally occurring amino acids, except methionine and cysteine. Addition of $1 \mathrm{mM}$ IPTG was used to induce $P_{t a c}$ promoter-mediated transcription. Twenty minutes after induction, cultures were pulse-labeled by addition of $37.5 \mu \mathrm{Ci}$ of $\mathrm{L}-\left[{ }^{35} \mathrm{~S}\right] \mathrm{me}$ thionine (sp. act. $>800 \mathrm{Ci} / \mathrm{mmole}$ ) per milliliter of cells. After 2 min, excess unlabeled L-methionine $(1.4 \mathrm{mg} / \mathrm{ml}$ of cells $)$ was added. At various times after this, $0.5-\mathrm{ml}$ aliquots of cells were removed and added to $35 \mu \mathrm{l}$ of an ice-cold mixture of protease inhibitors (60 mM PMSF, $30 \mathrm{mM} N$-ethylmaleimide (NEM), and $80 \mathrm{~mm}$ sodium azide) in $90 \%$ ethanol. To facilitate recovery of the labeled cells by centrifugation, $100 \mu \mathrm{l}$ of an unlabeled saturated culture of cells was added to each sample. Cells were lysed by boiling in $200 \mu \mathrm{l}$ of Laemmli sample buffer, and lysates were electrophoresed on $15 \%$ Laemmli gels. Gels were autoradiographed using Kodak X-Omat film, and band intensities in autoradiographs were measured using an LKB 2202 UltroScan laser densitometer. When chases were longer than $3 \mathrm{hr}$, cul- 
tures were diluted prior to labeling so that the $\mathrm{OD}_{600}$ was approximately 1.0 at the end of the chase.

Pulse-chase experiments using the isogenic $h t p R^{-} / h t p R^{+}$ strains CAG2039 and CAG2041 were conducted at $30^{\circ} \mathrm{C}$ because the mutant strain is inviable at $37^{\circ} \mathrm{C}$.

\section{Protein purification}

The wild-type 1-102 protein was purified as described previously (Parsell and Sauer 1989). The \# 105 protein was purified from E. coli strain MM294 F'lacIQ lacZ:: Tn5 carrying the plasmid encoding the \#105 protein. Cells were gown to an $\mathrm{OD}_{600}$ of $\sim 0.85$ in $\mathrm{M} 9$ minimal medium ( $100 \mathrm{ml}$ ) supplemented with casamino acids $(0.2 \%)$ and ampicillin $(150 \mu \mathrm{g} / \mathrm{ml}) . \mathrm{P}_{\text {tac }}$ promoter-mediated transcription was induced with $1 \mathrm{mM}$ IPTG, and cells were grown for an additional $1.5 \mathrm{hr}$ before harvesting. The cell pellet was frozen at $-20^{\circ} \mathrm{C}$. After thawing, the pellet was resuspended in one-tenth original volume of $S$ buffer $[0.1 \mathrm{M}$ Tris (pH 8), $5 \mathrm{mM}$ EDTA, 0.5 $\mathrm{M}$ sucrose, $0.12 \mathrm{~mm}$ PMSF, 0.05 mM NEM], and the suspension was centrifuged at $12,000 \mathrm{~g}$ for $15 \mathrm{~min}$. The supernatant containing the \#105 protein was loaded onto a 5-ml Affi-Gel Blue (Bio-Rad) column at $4^{\circ} \mathrm{C}$. The column was washed with $20 \mathrm{ml} \mathrm{SB}[10 \mathrm{mM}$ Tris- $\mathrm{HCl}(\mathrm{pH} 8), 2$ $\mathrm{mM} \mathrm{CaCl}, 0.1 \mathrm{mM}$ EDTA, $1.4 \mathrm{mM} \beta$-mercaptoethanol, $5 \%$ glycerol] plus $50 \mathrm{mM} \mathrm{KCl}$, and the \#105 protein was then eluted with a linear gradient $(50 \mathrm{ml})$ of $\mathrm{KCl}$ from $50 \mathrm{~mm}$ to $750 \mathrm{mM}$ in SB. Fractions containing the \#105 protein were pooled and concentrated using an Amicon YM-5 filter.

Thermal denaturation of the wild-type 1-102 and \#105 proteins was assayed by circular dichroism by measuring ellipticity at $222 \mathrm{~nm}$ as a function of temperature. For these studies the wild-type $1-102$ protein $(50 \mu \mathrm{g} / \mathrm{ml})$ and the \#105 protein $(\sim 25 \mu \mathrm{g} / \mathrm{ml})$ were in $10 \mathrm{~mm}$ potassium phosphate $(\mathrm{pH} 7), 100$ $\mathrm{mm} \mathrm{KCl}$.

\section{Preparation of ${ }^{35} \mathrm{~S}$-labeled proteins}

${ }^{35}$ S-labeled wild-type $1-102$ and \#105 proteins were purified as described above for the \#105 protein with the following modifications: Cells were grown to an $\mathrm{OD}_{600}$ of $\sim 1.0$ in $\mathrm{M} 9$ minimal medium $(40 \mathrm{ml})$ supplemented with ampicillin $(150 \mu \mathrm{g} / \mathrm{ml})$ and with each of the 20 naturally occurring amino acids except methionine and cysteine. IPTG was then added, and the cells were grown for $30 \mathrm{~min}$ prior to the addition of $1 \mathrm{mCi}$ of $\mathrm{L}-\left[{ }^{35} \mathrm{~S}\right]$ methionine (sp. act. $>800 \mathrm{Ci} / \mathrm{mmole}$ ). Before harvesting, the cells were grown for an additional $15 \mathrm{~min}$. The $\mathrm{S}$ buffer supernatant fraction containing either the $1-102$ or \#105 protein was loaded onto a 2-ml Affi-Gel Blue column. The column was washed with $8 \mathrm{ml} \mathrm{SB}$ plus $50 \mathrm{~mm} \mathrm{KCl}$, and the $1-102$ or \# 105 protein was eluted with $10 \mathrm{ml}$ SB plus $300 \mathrm{mM} \mathrm{KCl}$. Fractions containing the ${ }^{35} \mathrm{~S}$-labeled $1-102$ or \# 105 protein were stored at $-20^{\circ} \mathrm{C}$.

\section{Degradation assays in vitro}

E. coli cells of strain $\mathrm{X} 90 \mathrm{~F}^{\prime}$ lacI ${ }^{\mathrm{Q}}$ were grown to an $\mathrm{OD}_{600}$ of $\sim 1.0$ in 4 liters of LB. The cells were harvested, lysed by sonication, and the sonicate was centrifuged at $13,000 \mathrm{~g}$ for $45 \mathrm{~min}$. Nucleic acids and membranes were precipitated from the supernatant with polyethyleneimine (PEI, $0.1 \%$ ) and removed by centrifugation. Proteins in the PEI supernatant were precipated by the addition of ammonium sulfate to saturation and collected by centrifugation. The ammonium sulfate pellet was resuspended in SB plus $50 \mathrm{mM} \mathrm{KCl}$, was dialyzed against the same buffer, and was diluted into HIC buffer A $0.1 \mathrm{M}$ sodium phosphate ( $\mathrm{pH} 7$ ), $20 \%$ ammonium sulfate] prior to loading onto a 20-ml Phenyl-Sepharose CL-4B (Pharmacia) column at $4^{\circ} \mathrm{C}$. The column was washed with $50 \mathrm{ml}$ of HIC buffer A and developed with a linear gradient $(100 \mathrm{ml})$ from $20 \%$ to $0 \%$ ammonium sulfate in $0.1 \mathrm{M}$ sodium phosphate $(\mathrm{pH} 7)$. The protease activity was eluted by washing with an additional $20 \mathrm{ml}$ of $0.1 \mathrm{M}$ sodium phosphate ( $\mathrm{pH}$ 7). The eluent containing the protease activity was then dialyzed against $10 \mathrm{mM}$ Tris $(\mathrm{pH} 7.5)$ prior to use in protein degradation assays.

Degradation of ${ }^{35}$ S-labeled wild-type $1-102$ or \#105 protein by this partially purified, soluble $E$. coli fraction was measured

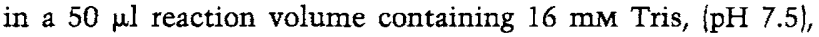
$5 \mathrm{mM} \mathrm{CoCl}_{2}$, and $0.02 \% \mathrm{NP}-40$ (to prevent the ${ }^{35} \mathrm{~S}$-labeled protein from adhering to the plastic tube). Reaction mixes contained $25 \mu \mathrm{l}$ of the $E$. coli fraction and $3 \mu \mathrm{l}$ of ${ }^{35}$ S-labeled 1-102 or \#105 protein $(\sim 10,000 \mathrm{cpm})$. Reactions were incubated at $37^{\circ} \mathrm{C}$ and were stopped (after $0,1,2,4$, or $24 \mathrm{hr}$ ) by transferring to ice and adding $130 \mu \mathrm{l}$ of $15 \%$ (wt/vol) TCA and $20 \mu \mathrm{l}$ of 20 $\mathrm{mg} / \mathrm{ml}$ bovine serum albumin. After at least $30 \mathrm{~min}$ on ice, the reaction mix was centrifuged, and $100 \mu l$ of the acid-soluble supernatant was added to $5 \mathrm{ml}$ of Hydrofluor (National Diagnostics). The sample was counted using an LKB 1211 Rackbeta liquid scintillation counter. Degradation was expressed as the percentage of radioactive label that became TCA-soluble as a function of time. In the experiments to determine whether degradation was ATP-dependent, the same procedure was followed with the addition of ATP (4 mM) and $\mathrm{MgCl}_{2}(5 \mathrm{~mm})$ to the assay mixture.

\section{Acknowledgments}

We thank Robert Cohen for communication of results prior to publication, Carol Gross for strains CAG2039 and CAG2041, Peter Kim for the use of the spectropolarimeter, the Pardue laboratory for the use of the scintillation counter, and Jim Bowie, Alan Grossman, Fred Goldberg, Mike Mossing, John ReidhaarOlson, and Kevin Shoemaker for valuable discussions and critical reading of the manuscript. We also thank one of the reviewers of this paper for suggesting that recognition of carboxyterminal amino acids may play a role in an intermediate step in protease La-mediated degradation. This work was supported by National Institutes Health grant 16892 and by a predoctoral grant from the Keck Foundation (D.A.P.)

\section{References}

Amman, E., J. Brosius, and M. Ptashne. 1983. Vectors bearing a hybrid $t r p-l a c$ promoter useful for regulated expression of cloned genes in Escherichia coli. Gene 25: 167-178.

Bachmair, A., D. Finley, and A. Varshavsky. 1986. In vivo halflife of a protein is a function of its amino-terminal residue. Science 234: 179-186.

Bachmair, A. and A. Varshavsky. 1989. The degradation signal in a short-lived protein. Cell 56: 1019-1032.

Baker, T.A., A.D. Grossman, and C.A. Gross. 1984. A gene regulating the heat shock response in Escherichia coli also affects proteolysis. Proc. Natl. Acad. Sci. 81: 6779-6783.

Bowie, I. U. and R.T. Sauer. 1989. Identification of C-terminal extensions that protect proteins from intracellular proteolysis. J. Biol. Chem. 264: 7596-7602.

Bukhari, A. I. and D. Zipser. 1973. Mutants of Escherichia coli with a defect in the degradation of nonsense fragments. $\mathrm{Na}$ ture 243: 238-241.

Cheng, H. H., P.J. Muhlrad, M.A. Hoyt, and H. Echols. 1988. 
Cleavage of the cII protein of phage lambda by purified HflA protease: control of the switch between lysis and lysogeny. Proc. Nat1. Acad. Sci. 85: 7882-7886.

Chung, C. H. and A.L. Goldberg. 1981. The product of the lon (capR) gene in Escherichia coli is the ATP-dependent protease, protease La. Proc. Natl. Acad. Sci. 78: 4931-4935.

Dice, J. F. 1987. Molecular determinants of protein half-lives in eukaryotic cells. FASEB J. 1: 349-357.

Dunten, R. L. and R.E. Cohen. 1989. Recognition of modified forms of ribonuclease $\mathrm{A}$ by the ubiquitin system. J. Biol. Chem. 264: 16739-16747.

Eisenberg, D. and A.D. McLachlan. 1986. Solvation energy in protein folding and binding. Nature 319: 199-203.

Evans, T., E.T. Rosenthal, J. Youngblom, D. Distal, and T. Hunt. 1983. Cyclin: A protein specified by maternal mRNA in sea urchin eggs that is destroyed at each cleavage division. Cell 33: 389-396.

Fauchere, J. and V. Pliska. 1983. Hydrophobic parameters $\pi$ of amino-acid side chains from the partitioning of aminoacetyl-amino-acid amides. Eur. I. Med. Chem. Chim. Ther. 18: $369-375$.

Goff, S.A., L.P. Casson, and A.L. Goldberg. 1984. Heat shock regulatory gene $h t p R$ influences rates of protein degradation and expression of the lon gene in Escherichia coli. Proc. Natl. Acad. Sci. 21: 6647-6651.

Goldberg, A.L. 1972. Degradation of abnormal proteins in Escherichia coli. Proc.Natl. Acad. Sci. 69: 422-426.

Goldberg, A.L. and A.C. St. John. 1976. Intracellular protein degradation in mammalian and bacterial cells: Part 2. Annu. Rev. Biochem. 45: 747-803.

Gottesman, S. and D. Zipser. 1978. Deg phenotype of Escherichia coli lon mutants. J. Bacteriol. 133: 844-851.

Gottesman, S., M. Gottesman, J. Shaw, and M.L. Pearson. 1981. Protein degradation in E. coli: The lon mutation and bacteriophage lambda $\mathrm{N}$ and cII protein stability. Cell 24: 225233.

Gottesman, S. 1987. Regulation by proteolysis. In Escherichia coli and Salmonella typhimurium. (ed. F.C. Neidhardt) pp. 1308-1313. American Society for Microbiology, Washington, D.C.

Grossman, A.D., D.B. Straus, W.A. Walter, and C.A. Gross. 1987. $\sigma 32$ synthesis can regulate the synthesis of heat shock proteins in Escherichia coli. Genes Dev. 1: 179-184.

Hanahan, D. 1983. Studies on transformation of Escherichia coli with plasmids. J. Mol. Biol. 166: 557-580.

Hershko, A. 1988. Ubiquitin-mediated protein degradation. $J$. Biol. Chem. 263: 15237-15240.

Kaiser, C.A., D. Preuss, P. Grisafi, and D. Botstein. 1987. Many random sequences functionally replace the secretion signal sequence of yeast invertase. Science 235: 312-317.

Katayama, Y., S. Gottesman, J. Pumphrey, S. Rudikoff, W.P. Clark, and M. Maurizi. 1988. The two-component, ATP-dependent Clp protease of Escherichia coli. I. Biol. Chem. 263: $15226-15236$.

Katayama-Fujimura, Y., S. Gottesman, and M.R. Maurizi. 1987. A multiple-component ATP-dependent protease from Escherichia coli. J. Biol. Chem. 262: 4477-4485.

Laemmli, U.K. 1970. Cleavage of structural proteins during the assembly of the head of bacteriophage T4. Nature 227: 680685.

Maniatis, T., E.F. Fritsch, and J. Sambrook. 1982. Molecular cloning: A laboratory manual. Cold Spring Harbor Laboratory. Cold Spring Harbor, New York.

Maurizi, M.R. 1987. Degradation in vitro of bacteriophage $\lambda \mathrm{N}$ protein by Lon protease from Escherichia coli. J. Biol. Chem. 262: 2696-2703.

Miller, J. 1972. Experiments in molecular genetics. Cold Spring Harbor Laboratory Press, Cold Spring Harbor, New York.

Mizusawa, S. and S. Gottesman. 1983. Protein degradation in Escherichia coli: The lon gene controls the stability of the SulA protein. Proc. Natl. Acad. Sci. 80: 358-362.

Oliphant, A.R., A.L. Nussbaum, and K. Struhl. 1986. Cloning of random-sequence oligodeoxynucleotides. Gene 44: 177183.

Pabo, C.O. and M. Lewis. 1982. The operator-binding domain of $\lambda$ repressor- structure and DNA recognition. Nature 298: 443-447.

Pabo, C.O., R.T. Sauer, J.M. Sturtevant, and M. Ptashne. 1979. The $\lambda$ repressor contains two domains. Proc. Natl. Acad. Sci. 76: 1608-1612.

Parsell, D.A. and R.T. Sauer. 1989. The structural stability of a protein is an important determinant of its proteolytic susceptibility in Escherichia coli. J. Biol. Chem. 264: 75907595.

Sanger, F., S. Nicklen, and A.R. Coulson. 1977. DNA sequencing with chain terminating inhibitors. Proc. Natl. Acad. Sci. 74: 5463-5467.

Smith, J.C., R.B. Derbyshire, E. Cook, L. Dunthorne, J. Viney, S.J. Brewer H.M. Sassenfeld, and L.D. Bell. 1984. Chemical synthesis and cloning of a poly(arginine)-coding gene fragment designed to aid polypeptide purification. Gene 32: $321-327$.

Spindler, K.R. and A.J. Berk. 1984. Rapid turnover of Adenovirus 5 early region 1A proteins. J. Virol. 52: 706-710.

Straus, D.B., W.A. Walter, and C.A. Gross. 1987. The heat shock response of $E$. coli is regulated by changes in the concentration of o32. Nature 329: 348-351.

1988. Escherichia coli heat shock gene mutants are defective in proteolysis. Genes Dev. 2: 1851-1858.

Torres-Cabassa, A.S. and S. Gottesman. 1987. Capsule synthesis in Escherichia coli $\mathrm{K}-12$ is regulated by proteolysis. J. Bacteriol. 169: 981-989.

Vershon, A.K., K. Blackmer, and R.T. Sauer. 1986. Mutation of the Arc repressor using synthetic primers with random nucleotide substitutions. In Protein engineering (ed. M. Inouye, and R. Sarmal pp.243-256, Academic Press, Orlando.

Weiss, M.A., M. Karplus, and R.T. Sauer. 1987. ${ }^{1} \mathrm{H}$ NMR aromatic spectrum of the operator binding domain of the $\lambda$ repressor: Resonance assignment with application to structure and dynamics. Biochemistry 26: 890-897.

Weiss, M.A., C.O. Pabo, M. Karplus, and R.T. Sauer. 1987. Dimerization of the operator binding domain of phage $\lambda$ repressor. Biochemistry 26: 897-904.

Zipser, D. and P. Bhavsar. 1976. Missense mutations in the lac $Z$ gene that result in degradation of the $\beta$-galactosidase structural protein. J. Bacteriol. 127: 1538-1542. 


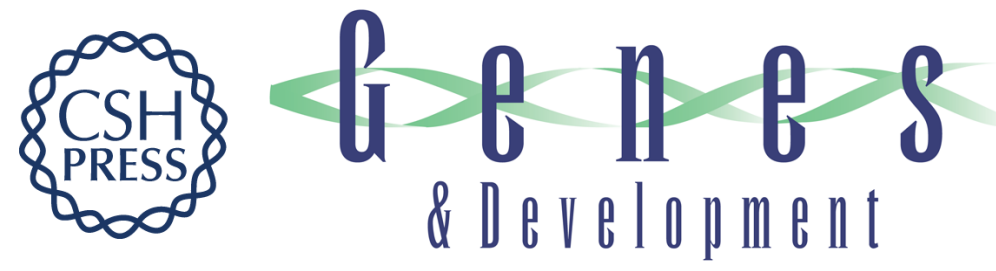

\section{Carboxy-terminal determinants of intracellular protein degradation.}

D A Parsell, K R Silber and R T Sauer

Genes Dev. 1990, 4:

Access the most recent version at doi:10.1101/gad.4.2.277

References This article cites 40 articles, 22 of which can be accessed free at: http://genesdev.cshlp.org/content/4/2/277.full.html\#ref-list-1

License

Email Alerting Service

Receive free email alerts when new articles cite this article - sign up in the box at the top right corner of the article or click here.

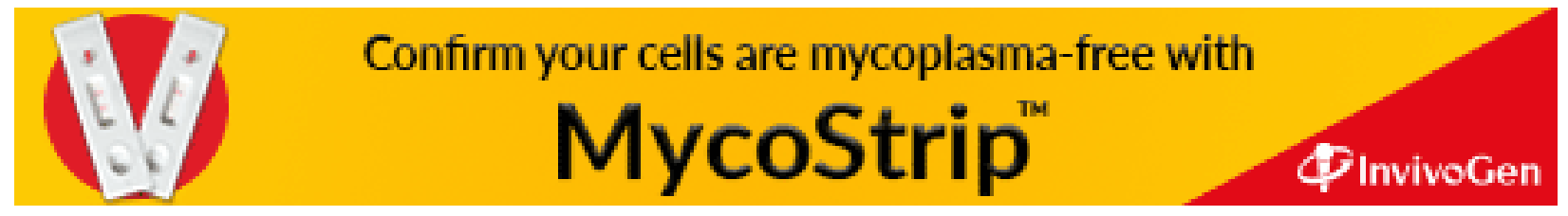

